\title{
A sonata de Bresson ${ }^{1}$
}

\author{
Luíza Alvim
}

Resumo: O cineasta francês Robert Bresson utilizou a música com bastante parcimônia em seus filmes, fazendo, muitas vezes, uma seleção de pequenos trechos de música clássica preexistente. Tal é o caso de $A$ grande testemunha (1966), em que podemos fazer analogias entre a maneira como os trechos da sonata D969 de Schubert são organizados no filme e as formas musicais da sonata original. Enfatizaremos, então, o bitematismo musical associado aos protagonistas Balthazar e Marie, a alternância dos trechos, além de considerarmos os aspectos comuns ao filme e à obra de Schubert, como a presença da natureza e a morte.

Palavras-chave: cinema; música; Robert Bresson; análise fílmica; formas musicais

Abstract: Bresson's sonata - French film director Robert Bresson used music sparingly in his films, often making a selection of short pieces of classical music. This is the case of Au hasard Balthazar [Balthazar, At Random] (1966), in which analogies can be drawn between the way the parts of Schubert's Sonata in A major D.969 are organized in the film and the musical forms the original sonata. To this end, we focus on the musical dualism associated with the protagonists Balthazar and Marie and the alternation of the parts, in addition to examining aspects shared by the film and Schubert's works, such as the presence of nature and death.

Keywords: cinema; music; Robert Bresson; film analysis; musical forms

\section{Introdução}

O cineasta francês Robert Bresson ficou conhecido pela parcimônia com que utilizou a música em seus filmes. Aproveitava, por exemplo, pequenos trechos do repertório clássico preexistente (utilizamos clássico no sentido de "erudito", não de "Classicismo"). Essa característica é comum a muitos diretores que Claudia Gorbman (2007) reúne como responsáveis por "música de autor" - entre outros, Jean-Luc Godard e Stanley Kubrick.

Nos filmes da fase intermediária ${ }^{2}$ da carreira de Bresson - a que correspondem Um condenado à morte escapou (Un condamné à mort s'est échappé, 1956), Pickpocket (1959), A grande testemunha (Au hasard Balthazar, 1966) e Mouchette (1967) - os trechos

1 Trabalho apresentado no Seminário Temático "Estudos do Som", na XV Socine, no Rio de Janeiro, em setembro de 2011.

2 O filme O processo de Joana d'Arc (Le procès de Jeanne d'Arc, 1962) pertence cronologicamente a essa fase, mas nele não é utilizada música preexistente do repertório clássico. 
de música clássica pertencem a uma única peça e são extradiegéticos, enquanto a música original é diegética.

Nesses filmes, tal música extradiegética confere certo contraste. Por exemplo, em $A$ grande testemunha, o lirismo romântico do Andantino em fá sustenido menor de Franz Schubert - o segundo movimento da sonata D959 de onde são retirados os trechos musicais extradiegéticos - acompanha algo bem mais prosaico, o jumento Balthazar em suas passagens de um dono a outro.

No entanto, Mc Donald (2007) afirmou que, diferente da ironia com que Stanley Kubrick fazia uso da música preexistente do repertório clássico, Bresson a emprega mais como sinergia do que como contraste. Em seu artigo, Mc Donald observa aproximações entre elementos da música e das imagens de $A$ grande testemunha. Mais do que isso, acreditamos que tal sinergia se faz também por meio de uma analogia entre a forma da distribuição dos trechos de Schubert no filme e a forma da música preexistente de que são oriundos.

Assim, buscaremos tais analogias em A grande testemunha,com a sonata D959. Além disso, vamos fazer associações com o período do Romantismo a que essa sonata de Schubert pertence ${ }^{3}$, inspirando-nos também no artigo "Schubert", de Theodor Adorno (1982), um dos primeiros que o filósofo escreveu sobre música.

Faremos referência a vários termos das disciplinas de análise musical e composição. Embora possa tornar mais difícil a compreensão por parte de um público não especializado, consideramos tal tipo de análise fundamental em trabalhos aprofundados sobre música no cinema, ausência notória nos estudos publicados sobre os filmes de Bresson, com exceção do artigo de Mc Donald (2007).

\section{Bresson, Schubert e o Romantismo}

Still sitz 'ich an des Hügels Hang, der Himmel ist so klar, das Lüftchen spielt im grünen Tal, wo ich beim ersten Frühlingsstrahl einst, ach, so glücklich war;

(Lied de Schubert, Im Frühling, a partir de poema de Schulze) ${ }^{4}$

3 Embora alguns considerem Schubert mais próximo ao Classicismo, esta sonata pertence ao último ano de vida do compositor, 1828, e várias de suas características nos permitem associá-la ao Romantismo.

4 Tradução nossa literal: "Tranquilo sento-me no declive da colina/ o céu está tão claro, / a brisa brinca no verde vale, / onde aos primeiros raios da primavera/ outrora, ah, tão feliz fui;" 
O personagem nomeado no título original do filme, Au hasard Balthazar, é um jumento cuja vida é mostrada desde a infância até a morte, numa pequena cidade do interior da França.

Balthazar é, portanto, parte da natureza, elemento muito importante no Lied ${ }^{5}$ - gênero de canção germânica com letra baseada em poemas preexistentes. Foi um gênero muito desenvolvido por Schubert e dele se nutriam bastante as suas sonatas para piano, como observam Massin (1993) e Patier (1994). É o caso da sonata D959, cujo quarto e último movimento retoma o tema do Lied Im Frühling ("Na primavera").

A natureza está também muito presente nos quadros do pintor romântico alemão Caspar David Friedrich, de que Patier (1994) se serve para ilustrar seu livro sobre Schubert. É bem verdade que a natureza em A grande testemunha não tem o caráter monumental das paisagens de Friedrich, sendo marcada pela crueldade, como nos livros de Georges Bernanos adaptados por Bresson em seus filmes Diário de um padre (Journal d'un curé de campagne, 1951) e Mouchette (1967). Por outro lado, semelhante aos personagens observadores de Friedrich, Balthazar é uma grande testemunha - como diz o título em português -, embora não exatamente de uma natureza majestosa, mas da vida daquela cidadezinha do campo francês.

Outra característica do Lied de Schubert é o espírito de Wanderschaft (wandern: andar ao léu), que corresponde no filme às andanças de Balthazar, especialmente quando é usado pelo personagem Arnold para transportar turistas na montanha. Um dos quadros de Friedrich se chama justamente Der Wanderer über dem Nebelmeer (1817), "O caminhante sobre o mar de névoa" (figura 1), assim como várias peças de Schubert apresentam a palavra Wanderer como título.

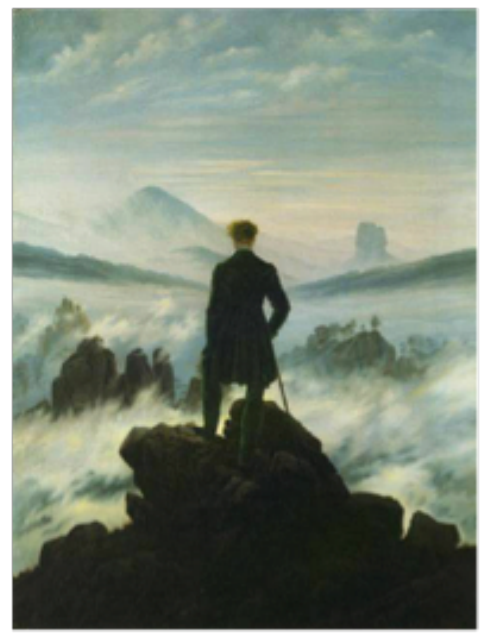

Fig.1. quadro Der Wanderer über dem Nebelmeer (1817), de Caspar David Friedrich.

5 Lied (plural Lieder) significa "canção" em alemão. Não se deve confundir o gênero Lied com a forma-Lied, uma das formas de movimentos de sonata, de que falaremos mais adiante. 
Brigitte Massin (1993) considera o Andantino da sonata D959 um canto de viagem, e o caráter de marcha está presente na própria estrutura da música. Afinal, a denominação Andantino já indica o andar, e a repetição obsessiva das notas dó no baixo lembra também os passos calmos e compassados do burrinho.

Também importantes no Lied são as imagens da morte. Sobre a música de Schubert, Adorno escreve: "Riacho, moinho e desertos negros de inverno, estendendo-se à meia-luz do sol, imemoriais, como no sonho, são os sinais da paisagem de Schubert, folhas secas, suas joias tristes; delas se desprendem os símbolos objetivos da morte"6 (ADORNO, 1982, p. 24). O filme de Bresson está igualmente semeado de mortes: a da irmã de Jacques, a de Arnold, a do pai de Marie, a do próprio Balthazar.

\section{Esquema geral da música em $A$ grande testemunha}

Assim como consideram Lindley Hanlon (1986) e outros autores, podemos dizer que há dois protagonistas no filme: Balthazar e a jovem Marie. Nas palavras de Jean-Luc Godard, Marie é "o outro burrinho" (GODARD, DELAHAYE, 1966, p. 30). Essa intenção de paralelismo é confirmada pelo próprio Bresson em entrevista:

Era preciso também - dado que a vida de um jumento é muito plana, muito serena achar um movimento, uma subida dramática. Então, era preciso achar um personagem que seria paralelo ao jumento e que teria esse movimento; que daria ao filme a subida dramática que lhe era necessário. Foi aí que eu pensei numa garota. Na garota perdida. Ou melhor: na garota que se perde (GODARD, DELAHAYE, 1966, p. 28).7

Hanlon (1986) também considera Arnold um duplo do burrinho por conta das humiIhações infringidas a ambos por Gérard, o líder da "turma do mal". Porém, pensando-se exclusivamente nos trechos musicais, enquanto Balthazar está sob a posse de Arnold, não ouvimos o Andantino, mas sim músicas diegéticas compostas por Jean Wiener, que não levaremos em conta neste trabalho.

Em considerações que se assemelham à metodologia que utilizamos aqui, Mc Donald (2007) vê nessa divisão uma referência à forma da partitura original. Com efeito, o Andantino da sonata D959, como geralmente é o caso dos segundos movimentos das sonatas, tem a forma tripartita característica da forma-Lied, com um trecho contrastante no meio e repetição variada da primeira parte ao final. Mc Donald (2007, p. 457) constata, portanto, uma concordância entre as durações de cada uma das partes do Andantino -

6 Tradução nossa, como de todas as outras citações em língua estrangeira: "Bach, Muhle und schwarze winterliche Einöde, im Zwielicht der Nebensonnen ohne Zeit wie im Traum sich erstreckend, sind die Zeichen der Schubertschen Landschaft, trockenen Blumen ihr traurige Schmuck; die objektiven Todensymbolen lösen sie aus".

7 "Il fallait aussi, étant donné que la vie d'un âne est une vie très égale, très sereine, trouver un mouvement, une montée dramatique. Il fallait donc trouver un personnage qui serait parallèle à l'âne, et qui aurait, lui, ce mouvement ; qui donnerait au film cette montée dramatique qui lui était nécessaire. C'est à ce moment que j'ai pensé à une fille. A la fille perdue. Ou plutôt : à la fille qui se perd." 
inicial $(34 \%)$, central $(44 \%)$ e final $(22 \%)$ - e a origem das músicas no filme, Schubert (32\%)-Jean Wiener (38\%)-Schubert (30\%).

No filme, há 11-12 trechos da música de Schubert (há uma interrupção nos créditos, o trecho 1 da tabela seguinte). A cada um dos protagonistas do filme, Balthazar e Marie, corresponderiam dois trechos do Andantino, que se repetem ao longo do filme em sua totalidade ou parcialmente. A eles daremos as letras A e B, respectivamente, na tabela 1 a seguir ${ }^{8}$. Na coluna da direita, fazemos referência ao modo como os trechos são ouvidos no filme, enquanto nas colunas do meio referimo-nos ao lugar que os trechos ocupam na partitura de Schubert ${ }^{9}$.

\begin{tabular}{|c|c|c|c|c|}
\hline Trecho & Tempo & Compassos & Na partitura original & No filme \\
\hline 1 & $0^{\prime}-$ & $\begin{array}{c}69-93 \\
94-108\end{array}$ & Parte central da música. & Prelúdio (créditos) \\
\hline 2 & $3^{\prime} 50^{\prime \prime}-5^{\prime} 42^{\prime \prime}$ & $1-50$ & Seções ${ }^{10}$ iniciais da música. & $\begin{array}{l}\text { Tema (A) de } \\
\text { Balthazar }\end{array}$ \\
\hline 3 & $9^{\prime} 25^{\prime \prime}-10^{\prime}$ & $147-158$ & $\begin{array}{l}\text { Transição da parte } \\
\text { central para o retorno } \\
\text { da parte inicial. }\end{array}$ & Tema (B) de Marie \\
\hline 4 & $24^{\prime} 30^{\prime \prime}-25^{\prime}$ & $177-188$ & Segunda seção variada. & $\left(A^{\prime}\right)$ \\
\hline 5 & $28^{\prime} 49^{\prime \prime}-29^{\prime} 23^{\prime \prime}$ & $147-158$ & Igual ao trecho 3. & (B) \\
\hline 6 & $64^{\prime} 24^{\prime \prime}-65^{\prime}$ & $1-18$ & Seção inicial da música. & (A) \\
\hline 7 & $73^{\prime} 58^{\prime \prime}-74^{\prime} 25^{\prime \prime}$ & 189-199 & Coda & $\left(A^{\prime}\right)$ \\
\hline 8 & $75^{\prime} 34^{\prime \prime}-75^{\prime} 54^{\prime \prime}$ & $159-166$ & Seção inicial variada. & $\left(A^{\prime \prime}\right)$ \\
\hline 9 & $76^{\prime} 58^{\prime \prime}-77^{\prime} 54^{\prime \prime}$ & $139-158$ & $\begin{array}{l}\text { Transição (no final } \\
\text { da parte central). }\end{array}$ & Transição + (B) \\
\hline 10 & $86^{\prime} 26^{\prime \prime}-87^{\prime} 30^{\prime \prime}$ & $155-176$ & $\begin{array}{l}\text { Final da transição e retorno } \\
\text { da parte inicial variada. }\end{array}$ & Final de $(B)+\left(A^{\prime \prime}\right)$ \\
\hline 11 & $90 \prime 11^{\prime \prime}-90 \prime 52 "$ & $1-16$ & $\begin{array}{l}\text { Seção inicial da música } \\
\text { (sem os dois últimos } \\
\text { compassos). }\end{array}$ & (A) \\
\hline
\end{tabular}

Tab.1. Esquema geral dos trechos em A grande testemunha

8 Embora não sejam exatamente os mesmo compassos, chamamos tanto o trecho 2 como o 6 de A pela característica geral da música. O mesmo fazemos com os trechos 4 e 7, considerando ambos como A’. Com efeito, a nossa classificação da coluna "No filme" é aproximativa.

9 Mc Donald (2007) faz uma tabela semelhante em seu artigo, com exceção da última coluna da direita ("No filme" ${ }^{\prime \prime}$, que acreditamos ser uma contribuição nossa em relação à aproximação dos trechos de música no filme com as formas musicais de origem.

10 "Parte", "seção", "frase" e "coda" são termos da análise musical. Como definido por Schönberg (1993), cada parte é dividida em seções e, cada seção, em frases. Já a coda é como um adendo final. 

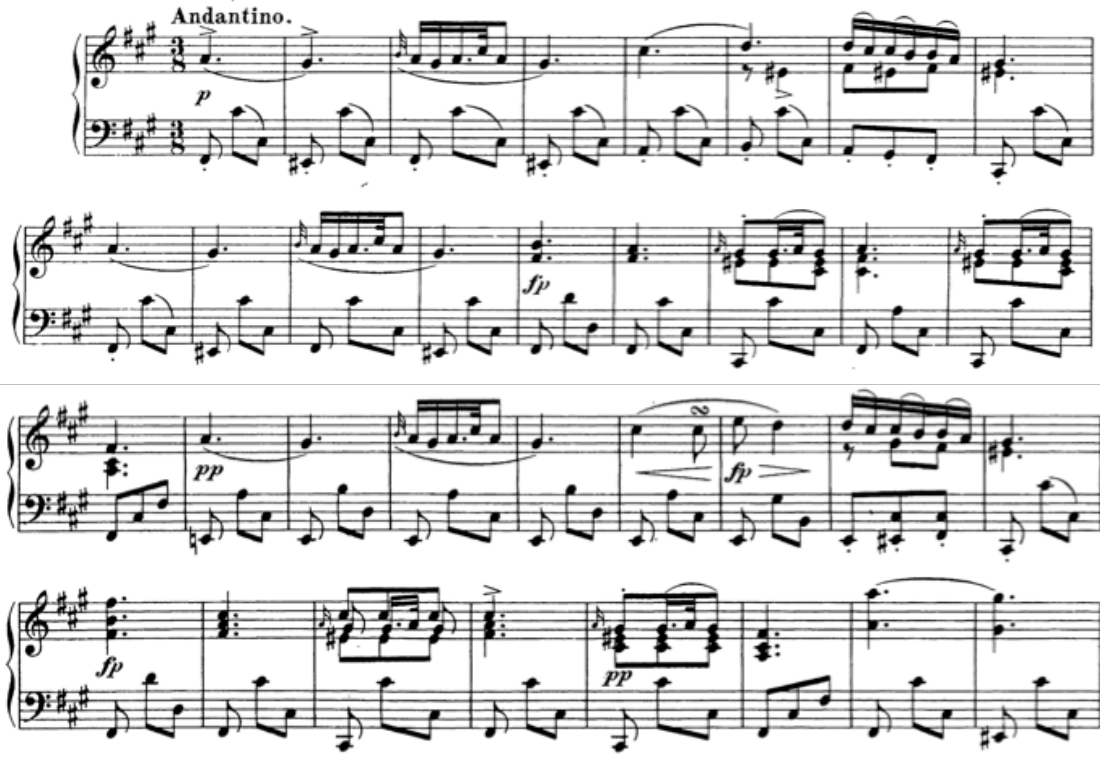

Fig.2. Compassos 1 a 34 do Andantino de Schubert, edição Breitkopf e Haertel. Tema A de Balthazar.
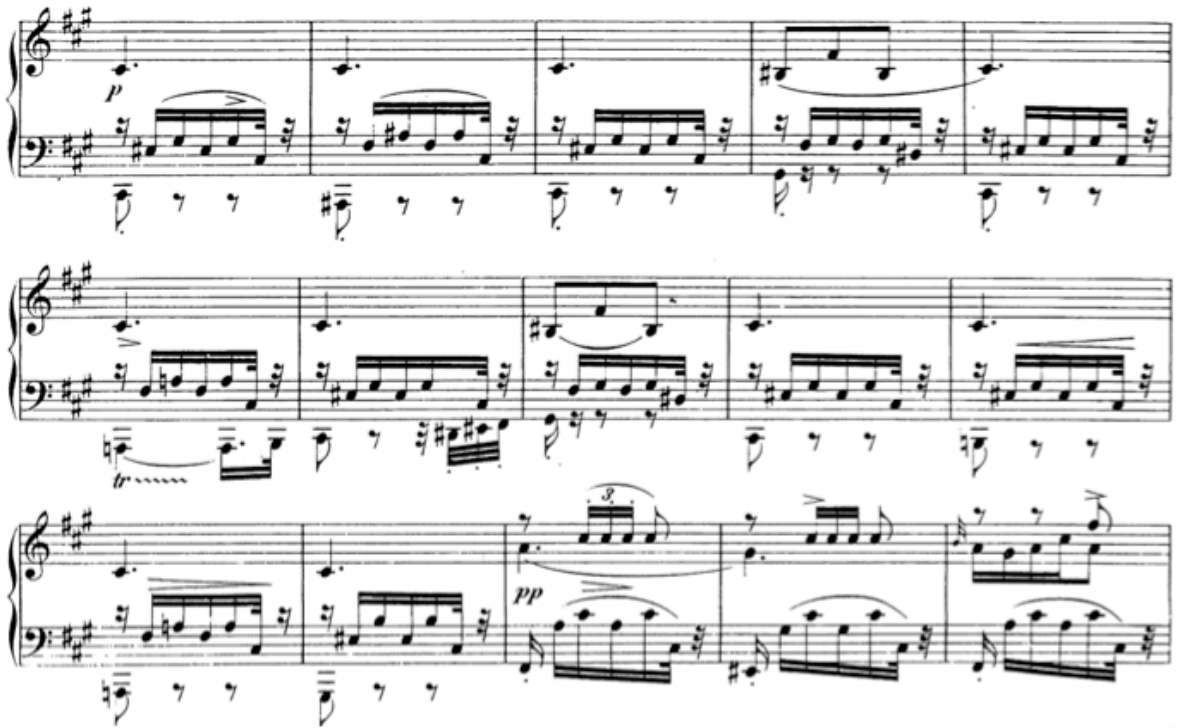

Fig.3. Compassos 147 a 161. Tema B de Marie e retorno com variação à parte inicial da música (tema de Balthazar). 


\section{Análise dos trechos musicais da sonata no filme}

Vamos agora apresentar todos os momentos do filme em que ouvimos os trechos do Andantino de Schubert, já indicando algumas analogias formais possíveis.

Como vimos na tabela 1, chamamos o trecho presente nos créditos, dividido em dois pelo zurro de Balthazar, de "prelúdio", pois ele é ouvido apenas nesse momento e antecede os outros trechos, todos retirados das partes mais líricas da música de Schubert.

Assim, numa maneira bastante incomum de começar um filme, Bresson utiliza a parte central do Andantino, considerada pela musicóloga Brigitte Massin (1993) um "momento alucinado de pura improvisação, destacado de todo o contexto, de liberdade total em sua organização, com harmonias sucessivas"11 (MASSIN, 1993, p. 1282).

Apesar de certa estranheza quanto ao caráter dessa "música de abertura" do filme, não deixa de haver um contraste, pois ela se alterna com algo prosaico e ruidoso, o zurrar diegético do recém-nascido Balthazar.

Na verdade, nesse momento, ocorre a transposição do "fantástico intervalo" entre os espaços extradiegético (a música) e diegético (o zurro) de que fala Robynn Stilwell (2007). A imagem do muro, sobre a qual se inserem o título e o restante dos créditos - um muro a ser transpassado como o da prisão de Um condenado à morte escapou -, reforça ainda mais esse aspecto de passagem.

Após esse prelúdio, e falando agora de cada um dos temas que identificamos em nosso esquema, observamos que $A$, tema de Balthazar, funciona quase como a "voz do burrinho". O próprio Bresson conta, em entrevista a Pierre Ajame (1966), que pensou no uso do Andantino como um leitmotiv de Balthazar: "Ele acompanha o asno quando a palavra lhe falta muito" (AJAME, 1966) ${ }^{12}$.

É interessante que, em outros filmes de Bresson dessa fase, como Um condenado à morte escapou e Pickpocket, a voz over seja um recurso fundamental, e Jean Sémolué (1993) lembra que Bresson havia pensado em fazer de A grande testemunha "o diário de um asno", cuja voz seria a do próprio diretor. Por outro lado, tendo em vista que as sonatas de Schubert se nutriam do Lied, uma peça vocal, sugere-se mais ainda a relação da voz de Balthazar com o seu tema musical.

(A) é repetido quatro vezes ao longo do filme, completo, em parte ou com variações. Ele está na primeira vez em que ouvimos música após os créditos. É como se Bresson apresentasse não só o tema, como também cenas da infância dos protagonistas. Nesta longa sequência, vemos assuntos muito caros também a Schubert: a amizade (de Jacques e Marie e das crianças com Balthazar) e a morte (a irmã moribunda de Jacques).

Mc Donald (2007, p. 460) chama a atenção para o balanço em que estão Jacques e Marie no início do trecho: seu movimento se faz quase junto com os tempos da música e

\footnotetext{
11 "moment halluciné de pure improvisation, détaché de tout contexte, d’une liberté totale dans son organisation, aux harmonies successives."

12 "Il accompagne l'âne quand la parole lui manque par trop."
} 
o seu som está mixado com ela. Na análise do autor, o movimento do balanço seria uma "manifestação visual" do próprio "balançar" da música de Schubert, com a oscilação da música entre tônica (I grau da escala) e dominante (V grau). A música também se aproxima de uma berceuse (canção de ninar), como observado por Keith Reader (2000).

O tema (A) volta a ser ouvido quando Balthazar passa a trabalhar para o comerciante de grãos, mesmo já velho e cansado (trecho 6). Nesse momento, temos apenas o início do que ouvíramos no trecho 1, como num resumo. Corresponde à primeira seção da música, sem o alívio dado pela modulação para lá maior, sugerindo, talvez, não haver muita esperança para o animal.

Voltamos a ouvir essa mesma parte, com exceção dos dois últimos compassos, durante a morte de Balthazar (trecho 11). Ela acontece numa clareira, na montanha, num retorno do animal à natureza e ao seu lugar de nascimento depois de toda uma vida entre os humanos. E vem, pela última vez, o Andantino fechar o ciclo, tal como "o vagar cíclico da forma de Schubert"13 (ADORNO, 1982, p. 26). A música de Schubert é aí pontuada pelos sinos das ovelhas que rodeiam Balthazar, dando ao burrinho, segundo Reader (2000), uma espécie de eternidade. Com efeito, após a morte do jumento, e cessada a música, só ouvimos os sinos, reforçando a continuação do ciclo da natureza.

Hanlon (1986) considera que a música em $A$ grande testemunha parece se referir à infância dos personagens, aos dias de inocência que já se foram, como a Combray de Proust. Não é à toa que, na segunda e na terceira vez em que o tema A é ouvido, está numa forma mais curta, que já provoca no espectador o reconhecimento do tema inteiro, como uma simples madeleine traz à memória de Proust toda a Combray de sua infância. No entanto, Hanlon (1986) observa que a repetição do tema A sugere, ao mesmo tempo, o sofrimento contínuo de Balthazar.

Já o tema B de Marie corresponde à modulação para dó sustenido maior na transição da tumultuada parte central da música para a volta das seções iniciais. Adorno se refere às modulações de maior para menor, e vice-versa, como base da transformação do modelo da sonata em Schubert em direção à profundeza da dimensão harmônica, sendo o modo menor a "sombra" do modo maior (ADORNO, 1982, p. 30). Usando uma palavra bem benjaminiana, Adorno afirma que a "salvação" ocorre nessa transformação de menor para maior: segue-se o "consolo" (Trost) ao "luto" (Trauer), trazendo uma esperança (p. 31).

Com efeito, na própria partitura de Schubert, tem-se a impressão de que, após o caos dos compassos anteriores, o caráter uniforme das seções iniciais da música seria transformado em sua volta (Mc DONALD, 2007, p. 453). Também no filme, o modo maior desvela uma esperança de felicidade para Marie. Na primeira vez em que o tema B aparece (trecho 3), Marie reencontra Balthazar, uma doce lembrança de sua infância. Mc Donald (2007) observa que, tal como o balanço no trecho 2, Marie acaricia Balthazar num certo ritmo, correspondendo a uma "manifestação visual" da música de Schubert.

13 "die kreisende Wandershaft Schuberts Form" 
Porém, assim como o trator do pai de Marie interrompe a música nesse trecho, tal promessa de felicidade não se confirma, o que é também sugerido na partitura, em que a esperança é "drenada para fora [...] com a inevitável descida de volta à tônica menor [fá sustenido menor] nos compassos 155-158" (Mc DONALD, 2007, p. 453) ${ }^{14}$.

Portanto, quando o tema (B) é repetido mais tarde (trecho 5), Marie está correndo de Gérard, num jogo sedutor que, se por um lado é promessa de alegria nas primeiras descobertas sexuais da menina, por outro é preocupante por conta do caráter duvidoso do rapaz ${ }^{15}$. É curioso que Marie corre em círculo - outra "manifestação visual" da música segundo Mc Donald (2007) - em torno de Balthazar, mas este, como "grande testemunha", é impotente para impedir o que se segue.

O erotismo dessa sequência pode parecer contrastante com o lirismo da música, mas Adorno (1982) alerta para uma falsa concepção sobre Schubert, ancorada no sentimentalismo romântico-burguês do século XIX, que teria levado a tornar kitsch a figura do compositor. Para Adorno, em vez de "um sonhador do início de século XIX, que se senta sempre ao lado do riacho e ouve o seu ruído" (ADORNO, 1982, p. 21) ${ }^{16}$, dever-se-ia pensá-lo com uma carga grande de erotismo, estando mais próximo ao lirismo do povo.

Na terceira vez (trecho 9), o tema B aparece precedido pelo que, na partitura, é, em sua transição, o final da sequência de modulações para dó sustenido maior. Jacques acabara de falar em casamento com Marie: talvez isso pudesse ser a ponte (outro nome para transição em música) para uma mudança na vida da moça, mas o que se segue é o tema B, quando Marie corre para "se explicar" com Gérard. Embora possamos já suspeitar que ela não conseguirá romper com ele, tem-se uma certa esperança de que isso aconteça. Porém, assim como logo se volta do modo maior para o tom menor principal, a influência da maldade de Gérard tornará trágico o destino de Marie.

Portanto, o Andantino também marca a vida amorosa de Marie. Se no início do filme víamos o menino Jacques declarando-Ihe o seu amor, a música também está na sedução de Gérard e quando Jacques, anos depois, a pede em casamento. Como resume Frodon (2007) no título do seu capítulo sobre o filme, A grande testemunha teria também como tema A conquista de Marie.

Como vimos antes, o tema A aparece nas formas variantes A'e A". Na música, A" corresponde à repetição variada de sua parte inicial, após a tumultuada parte central. No filme, na primeira vez (trecho 8), ouvimos A" quando Jacques está conversando com Marie sobre a possibilidade de casamento, ao lado de Balthazar pastando. Sendo a música derivada do tema do burrinho, poderia sugerir que tudo voltaria a ser como antes, na infância feliz. Porém, a interrupção do tema ao final de sua primeira frase musical (no quinto grau de fá sustenido menor, de efeito suspensivo), sem a frase de conclusão, deixa

14 No original, "drained away [...] by the inevitable descent back to the minor tonic in mm. 155-158".

15 Um dos subtítulos do livro de Hanlon (1986) é Probably the Devil: Gérard, numa referência ao filme posterior de Bresson, O diabo provavelmente (1977).

16 "der vormärzliche Träumer, der immerzu am Bähchlein sitzt, das er lauschen hört." 
essa possibilidade em suspenso ${ }^{17}$. De todo modo, como já se conhece o tema completo, pode-se suspeitar que o sonho de Jacques é impossível antes mesmo de ouvirmos o trecho 9 e do seguimento do filme.

Outra indicação do caráter fatal do destino dos personagens nesse trecho é, como observa Mc Donald (2007, p. 461), a nova figura rítmica que aparece nessa variação: os três dós sustenidos seguidos na voz superior, uma reminiscência do conhecido tema do destino da Quinta Sinfonia de Beethoven.

Na segunda vez em que ouvimos A"'(trecho 10), ele é precedido pelo final do tema B. Não há, nesse momento, a presença de Marie, mas sim de Gérard (numa lembrança, talvez, da moça, como indicado por seu tema): ele conduz Balthazar, carregado de mercadorias de contrabando. Dessa vez, o tema A" possui as duas frases, sendo finalizado na tonalidade principal de fá sustenido menor, tão inexorável como o destino do burrinho, fatalidade indicada, mais uma vez, na voz superior. Nesse trecho 10, a transformação dada pela variação de A em A" é ainda marcada pela violência que se imiscui na música com o som dos golpes de Gérard e seus comparsas em Balthazar.

Os dois trechos a que demos o nome de A' correspondem, na partitura de Schubert, à segunda seção variada e à coda. Relacionam-se, portanto, também a Balthazar. Assim, o trecho 4 é ouvido quando Marie salva Balthazar das maldades de Gérard. Ele começa como uma luz, na modulação para lá maior, porém, volta logo para fá sustenido menor. Nas palavras de Adorno (1982), há consolo, mas o que se segue é a tristeza, pois Balthazar continua sob o domínio de Gérard. Na verdade, se nos dirigirmos à partitura original, a continuidade entre os trechos 4 e 10 faz, como observa Mc Donald (2007), uma conexão entre essas duas partes do filme, e indica que Gérard levará Balthazar inexoravelmente para a morte.

O segundo, trecho 7, é ouvido quando os pais de Marie levam o burrinho para casa, como presente do mercador de grãos. Mais uma vez, há consolo, representado na música pela modulação passageira para o modo maior. Mas o luto se seguirá: a morte do pai de Marie e, depois, a de Balthazar.

Identificados todos os trechos do Andantino de Schubert, partiremos agora para a análise das formas musicais gerais que podemos apreender de sua seleção e distribuição no filme.

\section{Formas musicais}

O fato de termos identificado dois temas, (A) e (B), correspondentes a cada um dos protagonistas, leva-nos a pensar no bitematismo da forma-sonata. Essa forma musical é constituída por uma primeira parte de exposição de dois temas, o primeiro no tom principal e o segundo no tom da dominante (o quinto grau da escala), unidos por uma transição.

17 Segundo Zamarcois (1994), a frase musical é suspensiva quando seu fim não confere uma sensação de final absoluto, mas sim de um descanso provisório que precisa de uma continuação. É o caso do término na harmonia do quinto grau da escala. 
Segue-se o desenvolvimento desses temas, que são apresentados em outras tonalidades. Finalmente, há a reexposição dos dois temas no tom principal. Tal como a forma-Lied, a forma-sonata também tem três partes (exposição-desenvolvimento-reexposição), sendo uma repetida (a reexposição). Em termos gerais, o seu esquema seria o seguinte (tabela 2):

\begin{tabular}{|c|c|c|}
\hline Exposição & Desenvolvimento & Reexposição \\
\hline $\begin{array}{c}\text { tema } a+\text { transição }+ \text { tema b } \\
\text { (tom principal) (tom da dominante) }\end{array}$ & Temas a e b em outros tons & Temas a e b no tom principal \\
\hline
\end{tabular}

Tab.2. Esquema da forma-sonata

Em relação aos temas de cada personagem no filme, observamos que o tema A de Balthazar está na tonalidade principal da peça, fá sustenido menor, enquanto o tema $\mathrm{B}$ de Marie está em dó sustenido maior, tom da dominante.

Além disso, os temas da forma-sonata são geralmente contrastantes. Em conformidade com isso, vemos que o tema B de Marie tem um maior movimento. De fato, tanto Balthazar quanto Marie são personagens submissos (Balthazar a seus donos, Marie a Gérard), mas, no caso da moça, é uma "submissão revoltada", há certo contraste, a "subida dramática" pretendida por Bresson, como vimos na entrevista a Godard e Delahaye (2000) citada anteriormente.

Em relação à distribuição dos trechos no filme e ao desenrolar da história, observamos que, no início, quando o filme expõe os temas musicais de Balthazar e Marie, também são apresentados os protagonistas. No seu decorrer, os temas são modificados (embora não haja mudanças de tons, teremos $A^{\prime}, A^{\prime \prime}$, uma transição precedendo B), assim como os personagens: Balthazar cresce e passa por vários donos, Marie se aproxima de Gérard.

É claro, podemos dizer que em todo filme narrativo há um "desenvolvimento". No entanto, é interessante observar que na forma-sonata o desfecho é caracterizado por uma "reexposição". Também em A grande testemunha, haverá a reexposição de B e A, enquanto ambos os personagens terão um destino aproximado: Balthazar morre na natureza, na montanha onde nasceu, e Marie também se afasta da cidade e de Gérard (fica a dúvida se foi apenas uma fuga ou se ela buscou o suicídio, como a personagem do filme seguinte, Mouchette), talvez em direção à montanha de Balthazar.

Como na relação da exposição com a reexposição da forma-sonata, as imagens finais de Balthazar em meio às ovelhas nos evocam as iniciais do filme. Portanto, de certa forma, como consideram também Hanlon (1986) e Sémolué (1993), o filme "reexpõe" o seu começo. Podemos perceber isso no esquema presente no livro de Sémolué (1993, p. 136) em relação aos donos de Balthazar, que traduzimos e adaptamos abaixo, indicando justamente esse caráter de reexposição (figura 4). 


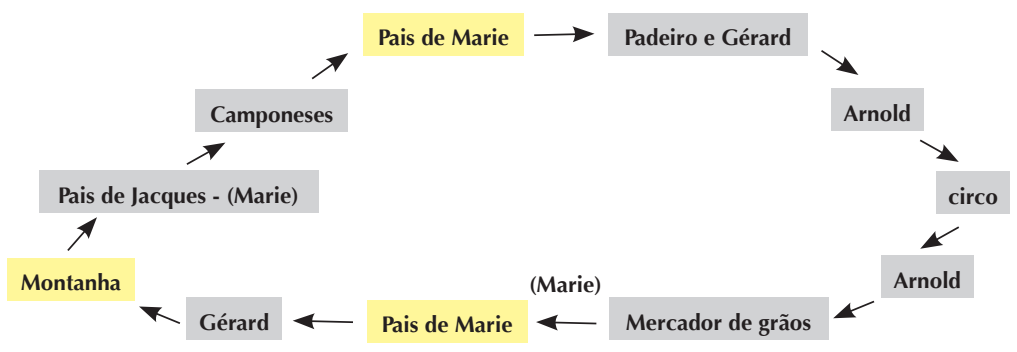

Fig.4. Esquema adaptado de Sémolué (1993) com a evolução dos donos e relações de Balthazar.

Por outro lado, podemos constatar que o tema A retorna constantemente ao longo do filme, seja como A, seja como A', seja como A". Isso também acontece com a seção inicial da forma-Lied, característica do Andantino. Além disso, o caráter da música é introspectivo, semelhante ao do Andantino e dos segundos movimentos de sonatas em geral. E Balthazar, personagem a que se associa o tema A, funciona como um fio condutor da história, o fio central em meio ao emaranhado da rede de fios narrativos que formam o filme. Afinal, ele é "a grande testemunha". Dessa maneira, poderíamos associar também o esquema dos trechos de Schubert no filme à forma-Lied, o que não deixa de ser uma forma musical de um movimento de sonata.

O próprio momento dos créditos do filme apresenta também um esquema que se aproxima da forma-Lied. Tal como sugeriram Hanlon (1986) e Mc Donald (2007), há nele três movimentos da trilha sonora: música-zurro-continuação da música. Assim como a posição da parte central do Andantino, ouvida nesse momento, o zurro de Balthazar está preso entre dois fragmentos de música (Mc DONALD, 2007, p. 458), barreiras sugeridas pela imagem do muro. Tal esquema não é exclusivo dos créditos deste filme: lembremo-nos dos esquemas tambores-clarim-tambores em O processo de Joana d'Arc (Le procès de Jeanne d'Arc, 1962), tambores-cornamusa-tambores em Lancelote do lago (Lancelot du lac, 1974) ou, ainda, acordes de violão-som do trânsito - acordes de violão em Quatro noites de um sonhador (Quatre nuits d'un rêveur, 1972).

Como vimos, o próprio esquema de toda a música de $A$ grande testemunha, dividida entre trechos de Schubert e a música original de Jean Wiener, aproxima-se dessa forma.

\section{Conclusão}

Bresson afirmou em várias entrevistas que a forma tinha precedência sobre o conteúdo. Foi considerado por muitos como um cineasta "frio, austero, seco", mas acreditamos que a emoção não esteja ausente de seus filmes e que muito do prazer obtido quando os vemos é decorrente das suas relações formais. 
Neste trabalho, para além das associações imagem-música observadas por Mc Donald (1994), como as "manifestações visuais" do "balanço" do trecho de Schubert, consideramos as analogias entre as formas musicais presentes na sonata D959 original e a maneira como os trechos de música estão distribuídos em A grande testemunha. Percebemos analogias tanto com a forma-sonata, por conta do bitematismo (Balthazar e Marie, os dois trechos do Andantino) e da reexposição de aspectos do início do filme no final (como a imagem da montanha), quanto com a forma-Lied, pelo constante retorno do tema A de Balthazar. O Romantismo da sonata de Schubert também se transmite ao filme em vários de seus aspectos.

Além disso, observamos que os trechos de música são selecionados a partir de procedimentos musicais como repetição e variação. Por isso consideramos que Bresson, ao montar sua "música de autor" (no sentido apontado por Gorbman, 2007), realiza um trabalho próximo ao de um compositor. O próprio diretor utilizou a palavra para definir o seu trabalho: "é a composição que faz o filme. Com efeito, se pegamos elementos que já existem, então, o que conta são as aproximações entre as coisas, e, a partir disso, finalmente, a composição"18 (GODARD, DELAHAYE, 1966, p. 29).

Luíza Alvim é doutoranda em Comunicação na UFRJ; encontra-se em estágio-sanduíche na Universidade Paris 3, com bolsa CNPq.

luizabeatriz@yahoo.com

\section{Referências}

ADORNO, T. Schubert. In: Musikalische Schriften IV. Frankfurt am Main: Suhrkamp, 1982.

AJAME, P. Le cinéma selon Bresson. In : Les Nouvelles Littéraires, 26 mai 1966.

FRODON, J. M. Robert Bresson. Paris: Le Monde, Cahiers du Cinéma, 2007. (Collection Grandes Cinéastes).

GODARD, J. L. ; DELAHAYE, M. La Question - entretien avec Robert Bresson. In : Cahiers du Cinéma, n.178, 1966, p. 26-35.

GORBMAN, C. Auteur music. In: GOLDMARK, D.; KRAMER, L.; LEPPERT, R. (Org.). Beyond the soundtrack: representing music in cinema. Los Angeles: University of California Press, 2007.

HANLON, L. Fragments: Bresson’s Film Style. New Jersey: Associated University Presses, 1986.

MASSIN, B. Franz Schubert. Fayard, 1993.

MC DONALD, M. Death and the donkey: Schubert at random in Au hazard Balthazar. In: Musical Quarterly, 90 (3-4), 2007, p. 446-468.

18 "c'est la composition qui fait le film. En effet, si nous prenons des éléments qui existent déjà, donc, ce qui compte, ce sont les rapprochements entre les choses, et, par-là, finalement, la composition." 
PATIER, D. Le promeneur solitaire. Paris: Gallimard, 1994.

READER, K. Robert Bresson. Manchester: Manchester University Press, 2000.

SCHÖNBERG, A. Fundamentos da composição musical. São Paulo: Edusp, 1993.

SÉMOLUÉ, J. Bresson. Paris: Flammarion, 1993.

SITLWELL, R. The fantastical gap between diegetic and nondiegetic. In: GOLDMARK, D.; KRAMER, L.; LEPPERT, R. (Org.). Beyond the soundtrack: representing music in cinema. Los Angeles: University of California Press, 2007.

ZAMARCOIS, J. Curso de formas musicales. Barcelona: Editorial Labor, 1994.

\section{Referências audiovisuais (por ordem cronológica)}

BRESSON, Robert. Diário de um padre (Journal d’un curé de campagne). França,1951, 35 mm, $115 \mathrm{~min}$.

Um condenado à morte escapou (Un condamné à mort s'est échappé). França, 1956, 35 $\mathrm{mm}, 99 \mathrm{~min}$.

Pickpocket, o batedor de carteiras (Pickpocket). França, 1959, 35 mm, 75 min.

O processo de Joana d’Arc (Le procès de Jeanne d'Arc). França, 1962, 35 mm, 65 min.

. A grande testemunha (Au hasard Balthazar). França/Suécia, 1966, 35 mm, 91 min.

Mouchette, a virgem possuída (Mouchette). França, 1967, 35 mm, 78 min.

Quatro noites de um sonhador (Quatre nuits d'un rêveur). França, 1972, 35 mm, 78 min.

Lancelote do lago (Lancelot du lac). França/ltália, 1974, 35mm, 85 min.

. O diabo provavelmente (Le diable probablement). França, 1977, 35 mm, 92 min.

Artigo recebido em julho

e aprovado em setembro de 2012. 